\title{
PERSEPSI DAN FAKTOR-FAKTOR YANG MEMPENGARUHI WISATAWAN MENGUNJUNGI OBJEK WISATA TETEMPANGAN HILL DI KAB.MINAHASA
}

\author{
Daisy Andih \\ Jurusan Pariwisata, Politeknik Negeri Manado \\ E-mail: deisyandih@yahoo.com
}

\begin{abstract}
Tetempangan Hill is one of the tourism objects in the land of Minahasa which becomes a favorite destination for both local, national and international tourists who want to enjoy the beauty of green hill view and the stretch of blue ocean. This research was conducted using Descriptive qualitative method and the data were collected using questionnaires distributed to respondents. The characteristics of tourists who visited Tetempangan Hill were dominated by male tourists with a percentage of $60 \%$ and the remaining $40 \%$ were female tourists and the tourist characteristics based on age were dominated by the tourists aged 15 to 29 years, followed by tourists aged 30 to 44 years. The tourists' perceptions based on attraction (attractiveness), accessibility (transportation), amenities (facilities) were dominated by positive perceptions except the food and drink kiosks which were negative. The factors that motivated the tourists to visit Tatempangan Hill were firstly, to see the natural beauty and secondly to accompany families and thirdly, to experience physical challenges, fourthly, to have relaxation /rest, fifthly, to enjoy something different and finally, to get closer to nature. It is suggested that the object operator add the menu sold at the food and drink kiosks considering that the tourists get problems with their food and drink needs since the kiosks only sell snacks and cup noodles.
\end{abstract}

Keywords: Perception, factors, tourist, tourism object

Absrak: Tetempangan Hill merupakan destinasi objek wisata yang merupakan salah satu destinasi objek wisata yang ada di tanah Minahasa dimana Destinasi objek wisata tetempangan hill adalah destinasi objek wisata yang menjadi favorit para wisatawan baik lokal, nasional maupun internasional yang ingin menikmati panorama indahnya pemandangan perbukitan yang hijau dan bentangan lautan biru yang indah. Metode penelitian ini dilakukan dengan menggunakan metode deskriptif yang bersifat kuantitatif. Teknik pengumpulan data melalui pengumpulan data dengan menggunakan kuesioner yang disebar kepada responden. Kharakteristik wisatawan yang mengunjungi objek wisata tetempangan hill didominasi wisatawan jenis kelamin laki-laki dengan prosentase $60 \%$ jenis kelamin laki-laki dan $40 \%$ wanita dan kharakteristik berdasarkan usia wisatawan didominasi berusia 15-29 tahun diikuti wisatawan yang berusia 30-44 tahun. persepsi wisatawan berdasarkan attraction (daya tarik), accesable (transportasi), amenities (fasilitas) dominasi positif. hanya kios tempat jualan makanan/minuman yang negatif. Faktor yang mendorong wisatawan mengunjungi objek wisata tetempangan hill pada urutan pertama adalah melihat keindahan alam kemudian urutan kedua mendampingi keluarga, selanjutnya urutan ketiga tantangan fisik selanjutnya pada urutan keempat ralaksasi/istirahat setelah itu diurutan kelima melihat sesuatu yang berbeda dan pada urutan terakhir keluar dari rutinitas. Untuk itu pihak pengelolah hendaknya menambah menu untuk dijual dikios tempat menjual makanan/minuman karena para wisatawan mengalami kesulitan untuk memenuhi kebutuhan makanan mereka disebabkan makanan yang disajikan hanya sebatas snack dan Mie Cup.

Kata Kunci : persepsi, faktor-faktor, wisatawan dan objek wisata 
Tetempangan Hill merupakan destinasi objek wisata yang merupakan salah satu destinasi objek wisata yang ada di tanah Minahasa dimana Destinasi objek wisata tetempangan hill adalah destinasi objek wisata yang menjadi favorit para wisatawan baik lokal, nasional maupun internasional yang ingin menikmati panorama indahnya pemandangan perbukitan yang hijau dan bentangan lautan biru yang indah. Destinasi objek wisata Tetempangan Hill terletak di Perkebunan desa Koha, Kecamatan Mandolang, Kabupaten Minahasa. Bukit Tetempangan berada di ketinggian 568 meter di atas permukaan laut . Objek wisata tetempangan Hill semakin digemari oleh wisatawan. Adapun wisatawan yang datang terdiri dari anak remaja, dewasa bahkan sampai orang tua. Untuk mengetahui mengapa destinasi objek wisata tetempangan Hill semakin hari semakin digemari inilah maka dianggap penting untuk melakukan penelitian. Penelitian ini dilakukan untuk mendapatkan informasi mengenai kharakteritik, persepsi wisatawan dan faktor -faktor yang mempengaruhi wisatawan mengunjungi objek wisata Tetempangan Hill di Kab.Minahasa. Sehingga dari hasil penelitian ini diharapkan bisa memberikan informasi bagi pihak-pihak yang berkepentingan. Masalah yang akan dibahas dalam penelitian ini adalah sebagai berikut: Bagaimanakah Karakteristik wisatawan yang mengunjungi objek wisata Tetempangan Hill Kab.Minahasa serta bagaiman persepsi wisatawan terhadap objek wisata Tetempangan Hill. Selain itu untuk menjelaskan faktor-faktor yang mendorong wisatawan mengunjungi objek wisata Tetempangan Hill di Kab.Minahasa

\section{Persepsi wisatawan}

Menurut Nugroho (2003:159-160) persepsi merupakan suatu proses yang timbul akibat adanya sensasi, dimana sensasi adalah aktivitas merasakan atau tanggapan yang cepat dari indera penerima kita terhadap stimuli dasar seperti cahaya, warna dan suara. Atau Persepsi adalah proses bagaimana stimuli-stimuli itu diseleksi, diorganisasikan dan diinterpretasikan. Sedangkan menurut Tatik Suryani (2008:102) persepsi pada hakekatnya merupakan proses psikologis yang kompleks yang juga melibatkan aspek fisiologis. Menurutnya ada dua faktor utama yang dijadikan pedoman konsumen yaitu layanan yang diterima dan layanan yang diharapkan. Wisatawan Menurut Spilanne, 1993 (dalam Rai Utama 2016) wisatawan adalah orang yang bepergian dari tempat tinggalnya untuk berkunjung ketempat lain dengan menikmati perjalanan dari kunjungannya itu. Medlik,1980 (dalam Ariyanto 2005), menjelaskan empat aspek (4A) yang harus diperhatikan dalam penawaran pariwisata. Aspekaspek tersebut adalah sebagai berikut:

1. Attraction (daya tarik); daerah tujuan wisata (selanjutnya disebut DTW) untuk menarik wisatawan pasti memiliki daya tarik berupa alam maupun masyarakat dan budayanya.

2. Accesable (transportasi); Accesable dimaksudkan agar wisatawan domestic dan mancanegara dapat dengan mudah dalam pencapaian tujuan ke tempat wisata.

3. Amenities (fasilitas); amenities memang menjadi salah satu syarat daerah tujuan wisata agar wisatawan dapat dengan kerasan tinggal lebih lama di daerah tujuan wisata (DTW).

4. Ancillary (kelembagaan); adanya kelembagaan pariwisata wisatawan akan semakin sering mengunjungi dan mencari DTW apabila didaerah tersebut wisatawan dapat merasakan keamanan, (protection of tourism) dan terlindungi.

\section{Aspek Permintaan Pariwisata}

Medlik (dalam Ariyanto,2005) menyebutkan faktor-faktor utama dan faktor lain yang mempengaruhi permintaan pariwisata sebagai berikut: 
1. Harga; harga yang tinggi pada suatu daerah tujuan wisata akan memberikan imbas atau timbal balik pada wisatawan yang akan bepergian, sehingga permintaan wisatapun akan berkurang begitu pula sebaliknya.

2. Pendapatan; apabila pendapatan suatu Negara tinggi, kecendrungan untuk memilih daerah tujuan wisata sebagai tempat berlibur akan semakin tinggi dan bisa jadi calon wisatawan membuat sebuah usaha pada daerah tujuan wisata jika dianggap menguntungkan.

3. Sosial Budaya; dengan adanya sosial budaya yang unik dan bercirikan atau berbeda dari apa yang adadinegara calon wisata berasal maka peningkatan permintaan terhadap wisata akan tinggi hal ini akan membuat sebuah keingintahuan dan penggalian pengetahuan sebagai khasanah kekayaan pola pikir budaya wisatawan.

4. Sospol (sosial politik); dampak sosial poilitik belum terlihat apabila kedaaan daerah tujuan wisata dalam situasi aman dan tentram, tetapi apabila hal tersebut berseberangan dengan kenyataan, maka sosial politik akan sangat terasa dampak dan pengaruhnya dalam terjadinya permintaan.

5. Intensitas keluarga; banyak atau sedikitnya keluarga juga berperan dalam permintaan wisata hal ini daoat diratifikasi, jumlah keluarga yang banyak maka keinginan untuk berlibur dari satu leuarga tersebut akan semakin besar, hal ini dapat dilihat dari kepentingan wisata itu sendiri.

6. Harga barang substitusi; disamping kelima aspek diatas, harga barang pengganti juga termasuk dalam aspek permintaan dimana barang-barang penggant dimisalkan sebagai pengganti DTW yang dijadikan cadangan dalam berwisata seperti Bali sebagai tujuan utama di Indonesia, akibat suatu dan lain hal Bali tidk dapat memberikan kemampuan dalam memenuhi syarat-syarat DTW sehingga secara tidak langsung wisatawan akan mengubah tujuannya kedaerah terdekat seperti Malaysia dan Singapira.

7. Harga Barang Komplementer; merupakan sebuah barang yang saling membantu atau dengan kata lain barang komplementer adalah barang yang saling melengkapi, dimana apabila dikaitkan dengan pariwisata barang komplementer ini sebagai objek wisata yang salaing melengkapi dengan objek wisata yang lainnya.

\section{Motivasi melakukan perjalanan wisata}

Motivasi dipandang sebagai bagian dari sisi kebutuhan dan keinginan psikologis maupun biologis, yang meliputi bagian yang tidak dapat dipisahkan yang dapat mendorong dan menarik seseorang untuk berbuat atau melakukan suatu aktivitas tertentu. Menurut McIntosh,1997 dan Murphy (dalam Pitana 2005) pada dasarnya seseorang melakukan perjalanan dimotivasi oleh beberapa hal, motivasi-motivasi tersebut dapat dikelompokkan menjadi empat kelompok besar sebagai berikut :

1. Physical or physiological motivation yaitu motivasi yang bersifat fisik antara lain untuk relaksasi, kesehatan, kenyamanan, berpartisipsi dalam kegiatan berolahraga, bersantai dan sebagainya.

2. Cultural motivation yaitu keinginan untuk mengetahui budaya, adat, tradisi dan kesenian daerah lain.

3. Social or interpersonal motivation yaitu motivasi yang bersifat sosial, seperti mengunjungi teman dan keluarga, menemui mitra kerja, melakukan kegiatan hal-hal yang dianggap mendatangkan gengsi (prestice), melakukan ziarah, pelarian dari situasi yang membosankan dan sebagainya.

4. Fantasy motivation yaitu adanya motivasi didaerah lain seorang yang akan bisa lepas dari rutinitas keseharian yang menjemukan dan yang memberikan kepuasan psikologis 
Sedangkan menurut Pearce (dalam Pitana,2005) berpendapat, wisatawan dalam melakukan perjalanan wisata termotivasi oleh beberapa beberapa kebutuhan yakni:

1. Kebutuhan fisiologis

2. Kebutuhan Keamanan

3. Kebutuhan Social

4. Kebutuhan Prestise

5. Kebutuhan Aktualisasi diri

\section{Faktor-faktor pendorong dan penarik wisatawan untuk berwisata}

Menurut Wu Qing Jin (dalam Rai Utama,2017) faktor-faktor wisatawan untuk berwisata teridir dari dua faktor yaitu:

1. Faktor-faktor yang mendorong wisatawan untuk berwisata adalah sebagai berikut:

a. To see culture and history, admire beautiful secebery, or enjoy the weather (melihat budaya dan sejarah, keindahan pemandangan, iklim dan cuaca)

b. Increase Knowledge (menambah pengetahuan)

c. Experience different lifestyles (pengalaman gaya hidup yang berbeda)

d. Fulfill one's travel dreams (mewujudkan impian)

e. Visit family and friends (mengunjungi keluarga dan teman-teman)

f. Be together with family members or friends (mendampingi keluarga atau teman)

g. Establish friendships, develop relationships (mempererat pertemanan, membangun hubungan)

h. Escape day to day (keluar dari rutinitas)

i. Rest and relax body and mind (instirahat dan relaksasi)

j. Relieve work pressure (menghindari tekanan pekerjaan)

k. Seek stimulation and excitement (mencari stimulasi dan kegembiraan)

1. Physical Challenge (tantangan fisik)

$\mathrm{m}$. Get close to and understand nature (mendekatkan diri dengan alam)

$\mathrm{n}$. See different things (melihat sesuatu yang berbeda)

2. Faktor-faktor yang menarik wisatawan untuk berwisata adalah sebagai berikut :

a. Tourism product, tourism charges (harga-harga produk pariwisata)

b. Distinctive lifestyles at one's destination (gaya hidup pada sebuah destinasi)

c. Interesting nightlife (tertarik kehidupan malam)

d. All Kind of good food (berbagai jenis makanan)

e. Convenient transport (kenyamanan transportasi)

f. Accommodation, sport facilities, and information (hotel,fasilitas olahraga dan informasi)

g. Quality of service (kualitas pelayanan)

h. Abundant historical and cultural resumbers, beautiful scenery, sunshine and comfortable weather (berbagai peninggalan sejarah dan budaya, keindahan pemandangan, matahari dan iklim yang nyaman)

i. Safety (jaminan keselamatan)

j. International metropolises (gaya hidup perkotaan internasional)

k. Peace, hygiene, comfort (kedamaian,kesehatan,kenyamanan)

1. Familiarity (keakraban, keramahan)

m. Good understand nature (pemahaman yang baik terhadap alam)

\section{METODE PENELITIAN}

Penelitian tentang persepsi dan faktor-faktor yang mempengaruhi wisatawan mengunjungi obejek wisata Tetempangan Hill adalah di Perkebunan desa Koha, Kecamatan Mandolang, 
Kabupaten Minahasa. Tetempangan Hill berada di ketinggian 568 meter di atas permukaan laut. Metode penelitian ini dilakukan dengan menggunakan metode deskriptif yang bersifat kuantitatif. Penelitian deskriptif dilakukan untuk mendapatkan gambaran tentang Karakteristik, Persepsi dan faktor-faktor yang mempengaruhi wisatawan mengunjungi obejek wisata Tetempangan Hill sedangkan metode penelitian kuantitatif menurut Sugiyono (2015: 13) merupakan analisis yang berupa angka-angka dan analisis yang menggunakan Statistic.Menurut Syofian Siregar (2017 : 25), skala likert adalah skala yang dapat digunakan untuk mengukur sikap, pendapat dan persepsi seseorang atau sekelompok tentang suatu objek atau fenomena tertentu. Teknik pengumpulan data melalui pengumpulan data yang dilakukan terhadap suatu objek dilapangan dengan mengambil sampel dari suatu populasi dengan menggunakan kuesioner sebagai alat pengumpul data yang disebar kepada responden (Samsudin Sulaiman dan Kusherdyana, 2013:23). Data primer bersumber dari hasil kuesioner yang langsung dari responden. Data yang diperoleh dari pihak pengelolah objek wisata Tetempangan Hill dan dari beberapa literature buku serta internet yang terkait dengan penelitian. Metode pengumpulan data yang digunakan dalam penelitian ini adalah sebagai berikut:

1. Metode survei: Dalam penelitian ini metode pengumpulan data adalah survei (mengunjungi lokasi penelitian) dengan menyebarkan kuesioner kepada para wisatawan disekitar tempat penelitian.

2. Metode wawancara: Dalam penelitian ini dilakukan wawancara dengan pihak pengelolah objek wisata melalui proses tanya jawab dalam secara lisan.

\section{HASIL DAN PEMBAHASAN}

Objek wisata Tetempangan merupakan salah satu objek wisata alam yang terletak di Minahasa khususnya terletak di Perkebunan desa Koha, Kecamatan Mandolang, Kabupaten Minahasa. Bukit Tetempangan berada di ketinggian 568 meter di atas permukaan laut . Destinasi objek wisata Tetempangan Hill ini menyajikan pemandangan alam yang sangat indah yakni hamparan pegunungan hijau dan lautan biru. Setiap orang yang datang akan merasakan kesejukan dan ketenangan. Responden adalah wisatawan laki-laki yang mengunjungi objek wisata Tetempangan Hill yaitu 18 orang atau $60 \%$ dan wisatawan wanita yaitu sebesar 12 wisatawan atau sebesar $40 \%$.

Tabel 1: Karateristik responden berdasarkan usia

\begin{tabular}{cllc}
\hline \multicolumn{2}{c}{ No Usia } & $\mathrm{n}$ (jumlah) & $\%$ \\
\hline 1 & $15-29$ tahun & 13 Orang & $43 \%$ \\
\hline 2 & $30-44$ tahun & 9 Orang & $30 \%$ \\
\hline 3 & $45-59$ tahun & 6 Orang & $20 \%$ \\
\hline 4 & 60 tahun keatas & 2 Orang & $7 \%$ \\
\hline & Total & 30 Orang & $100 \%$ \\
\hline
\end{tabular}

Sumber: Data Primer diolah, 2019

Dalam tabel 1 dapat dilihat karakteristik responden berdasarkan usia yakni usia 15-29 tahun sebesar 43\% atau sebanyak 13 wisatawan, 30- 44 tahun sebesar 30\% atau sebanyak 9 wisatawan, 45-59 tahun sebesar 20\% atau sebanyak 6 wisatawan dan diatas 59 tahun sebesar $7 \%$ atau sebanyak 2 wisatawan. Kharakteristik wisatawan yang mendominasi mengunjungi objek wisata Tetempangan Hill adalah wisatawan yang berusia 15-29 tahun diikuti wisatawan yang berusia 30-44 tahun. 


\section{Persepsi wisatawan terhadap objek wisata Tetempangan Hill}

Persepsi Wisatawan Berdasarkan Attraction (Daya tarik) dapat dilihat pada tabel 2 dibawah ini:

Tabel 2: Persepsi wisatawan berdasarkan attraction (daya tarik)

\begin{tabular}{|c|c|c|c|c|}
\hline No & Indikator & Skor & Frekuensi & Bobot \\
\hline \multirow[t]{5}{*}{1} & \multirow{5}{*}{$\begin{array}{l}\text { Keindahan Objek Wisata Tetempangan } \\
\text { Hill (Pemandangan alam) }\end{array}$} & 5 & 24 & 120 \\
\hline & & 4 & 6 & 24 \\
\hline & & 3 & - & - \\
\hline & & 2 & - & \\
\hline & & 1 & - & - \\
\hline & Total & & 30 & 144 \\
\hline \multirow{6}{*}{2} & \multirow{5}{*}{ Keramahan Masyarakat } & 5 & 14 & 60 \\
\hline & & 4 & 11 & 44 \\
\hline & & 3 & 5 & 15 \\
\hline & & 2 & - & - \\
\hline & & 1 & - & - \\
\hline & Total & & 30 & 119 \\
\hline \multirow{6}{*}{3} & \multirow{5}{*}{ Budaya Masyarakat Setempat } & 5 & 2 & 10 \\
\hline & & 4 & 13 & 52 \\
\hline & & 3 & 15 & 45 \\
\hline & & 2 & - & - \\
\hline & & 1 & - & - \\
\hline & Total & & 30 & 107 \\
\hline
\end{tabular}

Sumber: Data Primer, 2019)

Tabel 2 menunjukkan persepsi wisatawan berdasarkan keindahan objek wisata Tetempangan Hill dengan skor tertinggi yakni bobot 144 yang terdiri dari 24 responden menyatakan sangat indah sekali dan 6 responden menyatakan sangat indah diikuti dengan keramahan masyarakat dengan total bobot 119 yang teridiri dari 14 responden menyatakan sangat ramah sekali 11 responden menyatakan sangat ramah dan 5 responden menyatakan cukup ramah sedangkan budaya masyarakat setempat pada posisi terakhir yakni dengan total bobot 107 yang teridiri dari 2 responden menyatakan sangat berbudaya sekali , 13 responden menyatakan sangat berbudaya dan 15 responden menyatakan cukup berbudaya.

\section{Persepsi wisatawan berdasarkan accessibity (transportasi)}

Tabel 3 berikut ini menjelaskan tentang persepsi wisatawan berdasarkan accesable (transportasi)

Tabel 3: Persepsi wisatawan berdasarkan accesable (transportasi)

\begin{tabular}{cccc}
\hline \multicolumn{1}{c}{ Indikator } & Skor & Frekuensi & Bobot \\
\hline & 5 & 2 & 10 \\
\cline { 2 - 4 } Kemudahan transportasi menuju Objek & 4 & 11 & 44 \\
\cline { 2 - 4 } Wisata Tetempangan Hill & 3 & 17 & 51 \\
\cline { 2 - 4 } & 2 & - & - \\
\cline { 2 - 4 } & & 30 & 105 \\
\hline Total & & &
\end{tabular}

Sumber: Olahan data primer, 2019 
Tabel 3 menunjukkan persepsi wisatawan berdasarkan Accestable atau transporatasi menuju objek wisata Tetempangan Hill dengan total bobot 105 yang terdiri atas 2 responden menyatakan sangat mudah sekali , 11 responden menyatakan sangat mudah dan 17 responden menyatakan cukup mudah.

\section{Persepsi wisatawan berdasarkan amenities (fasilitas)}

Tabel 4 menjelaskan tentang persepsi Wisatawan Berdasarkan Amenities (fasilitas)

Tabel 4: Persepsi wisatawan berdasarkan amenities (fasilitas)

\begin{tabular}{|c|c|c|c|c|}
\hline No & Indikator & Skor & Frekuensi & Bobot \\
\hline \multirow{6}{*}{1} & \multirow{5}{*}{ Toilet } & 5 & 9 & 45 \\
\hline & & 4 & 14 & 56 \\
\hline & & 3 & 7 & 21 \\
\hline & & 2 & - & - \\
\hline & & 1 & - & - \\
\hline & Total & & 30 & 122 \\
\hline \multirow{5}{*}{2} & \multirow{5}{*}{ Tempat parkir } & 5 & 9 & 45 \\
\hline & & 4 & 19 & 76 \\
\hline & & 3 & 2 & 6 \\
\hline & & 2 & - & - \\
\hline & & 1 & - & - \\
\hline & Total & & 30 & 127 \\
\hline \multirow{6}{*}{3} & \multirow{5}{*}{ Gazebo (tempat berteduh) } & 5 & 5 & 25 \\
\hline & & 4 & 18 & 72 \\
\hline & & 3 & 7 & 21 \\
\hline & & 2 & - & - \\
\hline & & 1 & - & - \\
\hline & Total & & 30 & 118 \\
\hline \multirow{5}{*}{4} & \multirow{5}{*}{ Kios tempat jualan makanan/minuman } & 5 & - & - \\
\hline & & 4 & - & - \\
\hline & & 3 & - & - \\
\hline & & 2 & 11 & 22 \\
\hline & & 1 & 19 & 19 \\
\hline & Total & & 30 & 41 \\
\hline
\end{tabular}

Sumber: Olahan data primer, 2019

Tabel 4 menunjukkan persepsi wisatawan berdasarkan Amanities yang terdiri dari parkir objek wisata Tetempangan Hill dengan skor tertinggi yakni bobot 127 yang terdiri dari 9 responden menyatakan sangat bersih sekali dan 19 responden menyatakan sangat bersih dan 2 responden menyatakan cukup bersih diikuti dengan toilet dengan total bobot 122 yang teridiri dari 9 responden menyatakan sangat bersih sekali 14 responden menyatakan sangat bersih dan 7 responden menyatakan cukup bersih sedangkan gazebo atau tempat berteduh 5 responden menyatakan sangat bersih sekali 18 responden menyatakan sangat bersih dan 7 responden menyatakan cukup bersih. Kios tempat penjualan makanan/minuman pada posisi terakhir yakni dengan total bobot 41 yang terdiri dari 11 responden menyatakan tidak memadai dan 19 responden menyatakan sangat tidak memadai.Selain itu penelitian ini mengidentifikasi faktorfaktor yang mendorong wisatawan mengunjungi objek wisata tetempangan hill (Tabel 5); 
Tabel 5: Faktor-Faktor Yang Mendorong Wisatawan Mengunjungi Objek wisata Tetempangan Hill

\begin{tabular}{lc}
\multicolumn{1}{c}{ Faktor-faktor pendorong } & Frekuensi \\
\hline Melihat budaya dan sejarah, keindahan pemandangan, iklim dan cuaca & 11 \\
\hline Menambah pengetahuan & 0 \\
\hline Pengalaman gaya hidup yang berbeda & 0 \\
\hline Mewujudkan impian & 0 \\
\hline Mengunjungi keluarga dan teman-teman & 0 \\
\hline Mendampingi keluarga atau teman & 7 \\
\hline Mempererat pertemanan, membangun hubungan & 0 \\
\hline Keluar dari rutinitas & 1 \\
\hline Instirahat dan relaksasi & 3 \\
\hline Menghindari tekanan pekerjaan & 0 \\
\hline Mencari stimulasi dan kegembiraan & 0 \\
\hline Tantangan fisik & 6 \\
\hline Mendekatkan diri dengan alam & 0 \\
\hline Melihat sesuatu yang berbeda & 2 \\
\hline Total & 30 \\
\hline
\end{tabular}

Sumber : Data primer diolah, 2019

Pada tabel 5 menunjukkan bahwa faktor yang mendorong wisatawan mengunjungi objek wisata Tetempangan Hill dengan prosentase tertinggi adalah faktor keindahan alam sebanyak 11 responden diikuti mendampingi keluarga dan teman-teman sebanyak 7 responden, tantangan fisik 6 responden, istirahat dan relaksasi 3 responden, melihat sesuatu yang berbeda 2 responden dan terakhir keluar dari rutinitas 1 responden.

\section{SIMPULAN}

Berdasarkan hasil analisis maka dapat disimpulkan beberapa hal, sebagai berikut :

Karakteristik wisatawan berdasarkan jenis kelamin adalah wisatawan yang mengunjungi objek wisata Tetempangan Hill lebih banyak wisatawan yang berjenis kelamin pria yaitu 18 orang atau $60 \%$ dibanding jenis kelamin wisatawan yang berjenis kelamin wanita yaitu hanya sebesar 12 wisatawan atau sebesar $40 \%$. Karakteristik wisatawan yang mendominasi mengunjungi objek wisata Tetempangan Hill adalah wisatawan yang berusia 15-29 tahun diikuti wisatawan yang berusia 30-44 tahun. Persepsi wisatawan berdasarkan attraction (daya tarik) yang terdiri dari keindahan objek wisata Tetempangan Hill diurutan pertama kemudian diikuti keramahan dan terakhir budaya. Persepsi wisatawan berdasarkan accesable (transportasi) menunjukkan bahwasanya untuk kelokasi para wisatawan didominasi dengan cukup mudah menggunakan transportasi. Persepsi wisatawan berdasarkan amenities (fasilitas) yang terdiri dari toilet, pakir dan gazebo serta kios menjual makanan dan minuman, urutan pertama parkir kemudian toilet pada urutan kedua selanjutnya gazebo pada urutan ketiga dan terakhir kios menjual makanan/minuman. Faktor yang mendorong wisatawan mengunjungi objek wisata tetempangan hill pada urutan pertama adalah melihat keindahan alam kemudian urutan kedua mendampingi keluarga, selanjutnya urutan ketiga tantangan fisik selanjutnya pada urutan keempat ralaksasi/istirahat setelah itu diurutan kelima melihat sesuatu yang berbeda dan pada urutan terakhir keluar dari rutinitas.

\section{DAFTAR RUJUKAN}

Ariyanto (2005). Ekonomi Pariwisata Jakarta: http://www.geocities.com/ariyanto eks79/home.htm 
Pitana, I Gde. (2005). Sosiologi Pariwisata, Kajian Sosiologis Terhadap Struktur, Sistem Dan Dampak-Dampak Pariwisata. Yogyakarta: CV ANDI Offset

Prasetyo, Aji (2016). Faktor-Faktor Yang Mempengaruhi Keputusan Wisatawan Dalam Berkunjung Ke Objek Wisata Waduk Gajah Mungkur Wonogiri. SKRIPSI. Universitas Sebelas Maret. Surakarta

Samsudin Sulaiman,Kusherdyana, (2013). Pengantar Statistika Pariwisata; Aplikasinya Dalam Bidang Pariwisata, Usaha Perjalanan Wisata dan Perhotelan. Bandung: AlfaBeta.

Setiadi, J Nugroho, (2003). Perilaku Konsumen;Konsep dan Implikasi Untuk S Trategi dan Penelitian Pemasaran.Edisi 1. Jakarta: Prenada Media

Siregar, Syofian, (2017). Cetakan keempat. Metode Penelitian Kuantitatif Dilengkapi Dengan Perbandingan Perhitungan Manual \& SPSS. Jakarta Kencana

Sugiyono.(2015) Statistik Non Parametik Untuk Penelitian.Bandung: AlfaBeta.

Tatik Suryan, (2008). Perilaku Konsumen; Implikasi Pada Strategi Pemasaran.Edisi 1.Yogyakarta, Graha Ilmu.

Utama, I Gusti Bagus Rai. (2017). Pemasaran Pariwisata.Yogyakarta : CV.ANDI Offset Utama, I

Gusti Bagus Rai. (2016).Pengantar Industri Pariwisata ; Tantangan \& Peluang Bisnis

Kreatif. Cetakan Kedua. Yogyakarta: Penerbit Deepublish

Witarsana, I Kadek, (2017). Motivasi dan Persepsi Wisatawan Mancanegara Berwisata Alam Trekking Mountain Di taman Wisata Alam Gunung Batur Bukit Payang. Jurnal IPTA. Vol 5 No 1. 